\title{
O currículo prescrito no cotidiano escolar: interpretações de Coordenadoras Pedagógicas da Educação Infantil
}

\author{
The curriculum prescribed in daily school life: interpretations of \\ Pedagogical Coordinators of Early Childhood Education
}

\begin{abstract}
Thais Monteiro Ciardella
Mestre em Educação (Formação, Currículo e Práticas Pedagógicas) - FEUSP

Docente na Graduação em Pedagogia e Pesquisadora no Núcleo de Pesquisa e Extensão em Educação e Infância (NPEEI/Instituto Vera Cruz - São Paulo/SP/Brasil) ciardella.t@gmail.com

Marisa Vasconcelos Ferreira Doutora em Educação (Currículo) - PUC/SP Docente na Graduação em Pedagogia e na Especialização em Educação e Desenvolvimento na Primeira Infância e Coordenadora do Núcleo de Pesquisa e Extensão em Educação e Infância (NPEEI/Instituto Vera Cruz - São

Paulo/SP/Brasil)

marisavferreira@gmail.com
\end{abstract}

\begin{abstract}
Resumo: Este artigo apresenta recorte de pesquisa que teve como objetivo analisar, a partir de entrevistas e observações junto a coordenadoras pedagógicas de duas instituições de Educação Infantil da rede municipal de São Paulo - SP, as interpretações acerca de documentos curriculares oficiais da Educação Infantil e as formações das professoras em contexto, com vistas à condução das práticas pedagógicas, de forma consistente com as propostas presentes nos documentos oficiais. Neste artigo, focaremos os significados construídos pelas profissionais acerca das noções de criança e currículo, bem como de seu papel mediador no trabalho realizado com os documentos curriculares oficiais no âmbito da formação de professores, desde uma perspectiva qualitativa de referência sociocultural, buscando compreender relações, explicações, problematizações e reflexões empreendidas pelas coordenadoras, no âmbito da ação formativa. Destaca-se aqui a atividade de construção de significados e de ressignificações que faz parte da formação e que se concretiza na atuação da coordenação pedagógica, quando da apropriação do currículo prescrito, visando a sua concretização no currículo em ação e as dificuldades que as coordenadoras encontram em contextualizar a abordagem proposta pelas instâncias centrais.
\end{abstract}

Palavras- chaves: Coordenador Pedagógico. Currículo. Formação de professores. Educação Infantil.

Abstract: This article presents a research that aimed to analyze, through interviews and observations with the pedagogical coordinators of two early childhood education institutions of the municipal network of the city of São Paulo - state of São Paulo/Brazil, the interpretations about official curriculum documents of early childhood education and the teacher training actions in context, aiming to conduct pedagogical practices consistently, according to the proposals in official documents, elaborated through discussions about a new approach to this stage of education. In this article, we will focus on the interpretations produced during the training process of early childhood education teachers, which were analyzed from a qualitative perspective, through which we sought to understand relationships, explanations, questioning and considerations undertaken by the coordinators, within the context of training actions. We seek to highlight the activity of construction of meanings and resignifications that is part of the training and that occurs through the performance of the pedagogical coordination, when the prescribed curriculum is appropriated, aiming at its accomplishment in the practice of the curriculum in action and the difficulties that the coordinators find in contextualizing the approach proposed by the central instances.

Keywords: Pedagogical Coordination. Curriculum. Teacher training. Early Childhood education. 


\section{Introdução}

A atuação da coordenação pedagógica na Educação Básica tem sido significativamente conectada com a formação de professores no contexto da escola. Placco, Souza e Almeida (2012) afirmam, com base em pesquisas nacionais e internacionais, haver consenso quanto à importância da função de coordenação pedagógica (denominação que pode variar localmente) e o reconhecimento do seu papel articulador da formação no contexto da escola. Apesar de bastante reconhecida essa relação da coordenação com a formação da equipe, e, de certa forma, plenamente aceita, é preciso ressaltar que o perfil desse profissional se modificou da ideia de inspeção escolar para uma que se supõe mais formativa.

Davis et al (2012, p. 67) identificam o reconhecimento da coordenação pedagógica no âmbito da formação continuada na escola, e, ao mesmo tempo, a diversidade de condições concretas de configuração dessa atuação, que se modifica a depender de fatores como a concepção e as modalidades de educação continuada, bem como os norteamentos da política de formação de professores e, acrescentamos, dos documentos curriculares.

Na rede estadual Paulista, Vera e Fernandes (2019), a partir de análise da oferta de cursos de formação pela Escola de Formação de Professores (EFAP), no período de 2010 a 2018, identifica ações formativas pontuais, padronizadas e distantes do contexto real das escolas, além de pouco favoráveis à participação articulada dos professores-coordenadores.

O presente artigo se situa no lugar daqueles que reconhecem e valorizam a atuação do coordenador pedagógico na formação continuada desenvolvida no contexto da escola e se preocupa com a complexidade da tarefa demandada a este profissional e as condições de trabalho ofertadas, especialmente em períodos de intensa reformulação curricular - tal como o que vivemos a partir da homologação da Base Nacional Comum Curricular BNCC (Brasil, 2017), a revisão dos currículos municipais e estaduais, e a consequente reorganização dos projetos político-pedagógicos das escolas.

Tendo isso em vista, o objetivo geral da pesquisa que deu origem ao recorte aqui apresentado consistiu em analisar como coordenadoras pedagógicas interpretam documentos curriculares propostos para a Educação Infantil da rede municipal de São Paulo e como organizam e desenvolvem ações de formação no âmbito da instituição, junto à equipe de professoras ${ }^{1}$. Para tanto, foram realizadas entrevistas com duas coordenadoras pedagógicas da rede municipal de São Paulo, sendo uma coordenadora de Centro de Educação Infantil - CEI (atende crianças de zero a

\footnotetext{
${ }^{1}$ Manteremos professoras no feminino pois, nas duas unidades pesquisadas, apenas mulheres compunham a equipe docente.
} 
três anos) e uma coordenadora de Escola Municipal de Educação Infantil - EMEI (atende crianças de quatro e cinco anos), buscando investigar sentidos e significados que emergem no processo de apropriação dos documentos e suas decorrências para o currículo em ação (CIARDELLA, 2019).

Nesse momento histórico de políticas curriculares voltadas à elaboração de documentos oficiais, ir à escola significou compreender as relações entre o currículo prescrito e o currículo em ação (SACRISTÁN, 1988), em um contexto onde, embora a consolidação da Educação Infantil enquanto etapa inicial da Educação Básica já seja reconhecida socialmente, a preocupação com as práticas pedagógicas ainda se coloca. Pesquisas realizadas por Campos, Fullgraf e Wiggers (2006) e por Barbosa (2010) mostram que as últimas décadas se caracterizaram pela definição de currículos que privilegiam a criança como sujeito ativo na construção de conhecimento e, nessa perspectiva, têm seu desenvolvimento valorizado, mas, contraditoriamente, as práticas pedagógicas mantêm resquícios de uma perspectiva de preparação da criança para o Ensino Fundamental, o que descaracteriza o trabalho pedagógico específico da Educação Infantil.

Contudo, é preciso reconhecer a abrangência do debate curricular na Educação Infantil nas últimas décadas, pós-constituição de 1988, e os avanços empreendidos, que, em âmbito legal, fortaleceram o espaço da Educação Infantil enquanto primeira etapa da educação básica - nos direcionando para pensar na pluralidade de currículos em ação nas instituições.

Nesse cenário, entendemos que a escola assume "uma certa margem de autonomia" (LIMA, 1998, p. 35) na concretização de seus currículos e projetos pedagógicos, sendo necessários estudos que conheçam, problematizem e valorizem as formas como os atores se organizam, afinal,

[...] os actores escolares não se limitam ao cumprimento sistemático e integral das regras hierarquicamente estabelecidas por outrém, não jogam apenas um jogo com regras dadas a priori, jogam-no com a capacidade estratégica de aplicarem selectivamente as regras disponíveis e mesmo de inventarem e construírem novas regras (LIMA, 2008, grifos das autoras).

A partir dessa autonomia relativa de ação, a escola constrói currículo e, nessa construção, os profissionais que ali atuam aprendem sua profissão. Pesquisar esse movimento significa valorizar a formação centrada na escola (MATE, 2005), levando em conta a dimensão de seu contexto organizacional.

Enfocar essa dimensão da concretização curricular não significa minimizar as demais, especialmente, o âmbito de elaboração dos documentos oficiais. O escopo deste artigo não comportaria, mas é um bom exemplo desse processo de construção de documentos curriculares, o cenário de disputa de significados que predominaram no texto da Base Nacional Comum Curricular - etapa da Educação Infantil (BRASIL, 2017), assim como os diversos interesses que 
estavam em jogo, constituindo as condições de produção do texto normativo e que, portanto, não podem ser ignoradas ao se refletir sobre seu desenvolvimento curricular e sobre a passagem do documento curricular nacional para as construções das propostas estaduais e municipais. $O$ movimento de interpretação e documentação dos textos curriculares e as ações que decorrem daí, configuram um ciclo de mediações que envolve diferentes atores, com suas referências conceituais e metodológicas, desejos e posições ético-políticas, em um cenário socioeconômico complexo e dialético. Constituir documentos que garantam o alinhamento com os princípios da escola democrática, das pesquisas contemporâneas da educação e da participação dos profissionais da educação é de fundamental importância para que esses textos possam contribuir com as escolas e redes de ensino, que por sua vez, trabalharão com esses documentos, a partir da realidade de seu projeto pedagógico e comunidade escolar. Essas construções locais também influenciam a definição dos textos oficiais (por meio de resistências, adesões, práticas que se modificam ou não, consultas públicas etc.).

Nessa direção, as inspirações que advieram do estudo aqui apresentado nos ajudam a entender como diferentes atores do cenário educacional se apropriam dos documentos oficiais elaborados no percurso histórico da Educação Infantil, a partir da aprovação recente da Base Nacional Comum Curricular, quando se cria uma forte expectativa em torno dos caminhos de implementação desse documento pelas políticas públicas.

O debate em torno dessas expectativas nos dá pistas para mapear possibilidades criativas de leitura desses documentos e de construção contextualizada das ações formativas e dos projetos pedagógicos, no âmbito das escolas, das redes de ensino e das instituições de formação de professores. As observações da pesquisa se dão em nível das ações formativas organizadas pelas coordenadoras, que as promovem a partir de suas interpretações dos documentos curriculares. No entanto, nessas formações, novos significados e interpretações serão construídos também pelas professoras, antes de chegarem a suas práticas com as crianças, em um movimento que configura o currículo em ação.

\section{Metodologia}

A primeira etapa do estudo se dedicou a realizar uma pesquisa bibliográfica sobre o tema do currículo na Educação Infantil e uma pesquisa de documentos curriculares oficiais específicos desta etapa da Educação Básica. Esse conjunto de textos nos levou a construir uma "linha do tempo", organizadora das relações entre documentos curriculares e referências que subsidiam a organização do trabalho pedagógico. 
Em momento seguinte a essa imersão nos documentos, construímos roteiros de entrevista semiestruturada e, em campo, entrevistamos duas coordenadoras de unidades de Educação Infantil da rede municipal São Paulo:

- CP1 (Pedagoga, especialista em Gestão Pedagógica e Formação na Educação Infantil, concursada desde 1985 e atuando há onze anos como coordenadora pedagógica, sendo que há dois anos no mesmo CEI, que conta com quatorze professores e 113 alunos);

- CP2 (Pedagoga, concursada também desde 1985 e atuando como coordenadora há 27 anos, há três anos na mesma EMEI, que conta com oito professoras e 141 alunos).

Optou-se por selecionar uma CP de CEI e uma de EMEI, para abranger experiências que decorressem do olhar para os dois segmentos que compõem a Educação Infantil e, na RME de São Paulo, localizam-se em distintas instituições. Visou-se a imersão mais aprofundada no contexto de trabalho das participantes da pesquisa, realizando-se, além das entrevistas, observações dos espaços da Educação Infantil e leituras de registros dos processos formativos, de forma a perceber, de forma mais concreta, como as coordenadoras pedagógicas significavam as condições concretas de sua atuação.

O material das entrevistas foi registrado em áudio e transcrito integralmente e organizado segundo seu conteúdo, a partir das aproximações entre as variadas respostas. A partir dessa organização, os dados foram interpretados, confrontados e analisados com base na bibliografia utilizada (LUDKE e ANDRÉ, 1986, p.45).

Os temas norteadores das entrevistas abrangeram:

- as representações das coordenadoras em torno da sua função,

- as interpretações sobre os documentos orientadores do currículo para a Educação Infantil, e,

- a condução dos processos formativos nesse contexto (desafios que identificam em relação à apropriação dos conceitos, pela equipe de professores).

A partir da noção de que a formação do professor consiste em processos de "apropriação e construção de formas de pensar, sentir, agir em situações de ensino e de atribuir significados a seus componentes, segundo uma matriz ideológica que se constitui social e historicamente" (OLIVEIRA et al. 2011, p. 16), buscamos analisar como as coordenadoras pedagógicas 
significavam aspectos destacados dos documentos curriculares e identificados como necessários à formação da equipe de professores, destacando no escopo deste texto significados construídos em torno das noções de criança e de currículo, bem como a compreensão acerca do papel mediador da formação de professores, concretizada na atuação da coordenação pedagógica.

\section{Análise}

Com objetivo de compreender interpretações feitas a partir das leituras dos documentos curriculares e aproximações e distanciamentos que refletissem significados acerca de criança, currículo e os documentos curriculares em questão, durante as entrevistas com ambas coordenadoras, não perguntamos sobre um documento específico, convidando as entrevistadas a falarem sobre o momento político de definição de um currículo para a Educação Infantil. Avaliamos que, com esse convite, foi possível identificar quais são os documentos que realmente alicerçam a prática das profissionais. Os documentos mais citados foram o Referencial Curricular Nacional para a Educação Infantil - RCNEI (Brasil,1998) e as Diretrizes Curriculares Nacionais para a Educação Infantil - DCNEI (Brasil, 2009). O documento municipal Currículo Integrador da Infância Paulistana (São Paulo, 2015) é citado pelas Coordenadoras, mas as falas não trazem dados que possibilitem afirmar sua influência no trabalho de formação.

Toda a entrevista com as coordenadoras é marcada por uma tentativa por parte das entrevistadas de "contextualizar" o momento de definição de um currículo para a Educação Infantil, mostrando que o currículo prescrito está localizado em um cenário maior de pesquisas acadêmicas que redefinem o conceito de criança e de práticas pedagógicas com crianças pequenas.

Em relação aos elementos comuns entre as falas das profissionais, as duas coordenadoras concordam que existe "uma marcação [legal] muito clara hoje da transformação da concepção de criança" (CP2, entrevista) e existe um movimento legal de "valorizar mais aquilo que é da linguagem da infância, aquela escuta da criança” (CP1, entrevista). Essas afirmações situam historicamente uma demarcação do espaço do conhecimento teórico específico da Educação Infantil - nas últimas décadas, as produções brasileiras (nos âmbitos legal e acadêmico) podem ser traduzidas por um movimento de construção de um campo de estudo específico, fortalecido pelos documentos oficiais que definem a especificidade da infância (BRASIL, 2009; BRASIL, 2016).

A CP2, que iniciou sua carreira na Educação Infantil na década de 1980, e no início de 1990 até 2014 permaneceu no Ensino Fundamental, ao retornar para a Educação Infantil nesse contexto de divulgação de documentos norteadores de um currículo, apresenta uma fala que demarca bem esse território: "Eu perdi o ano que vieram as DCNEI, mas quando eu voltei, eu identificava uma 
mudança" (CP2, entrevista).

A CP1 também percebe avanço significativo nas produções sobre Educação Infantil, principalmente em relação à valorização dos saberes das crianças bem pequenas. Ela afirma que as professoras que entraram nos últimos concursos (refere-se ao ano de 2010 em diante), "chegam em um momento muito fortalecido já de discussões - principalmente no CEI. Dizer que não há avanços seria muita falta de generosidade da minha parte. O CEI está anos luz a frente da EMEI, muitos anos luz a frente da EMEF” (CP1, entrevista).

As duas falas são marcadas por afirmações sobre a necessidade de: não transformar a educação infantil em um "mini-ensino fundamental" (CP2, entrevista), entender que existe "todo um movimento para a criança aprender" (CP2, entrevista) e entender que existem representações culturais a respeito do que seja criança, professora e escola (CP1, entrevista).

Portanto, ao discutir um currículo para a Educação Infantil, as coordenadoras pedagógicas apontam um cenário que se caracteriza ainda pela necessidade de se distanciar do Ensino Fundamental (no sentido de não "emprestar" um currículo formulado para os anos seguintes), para valorizar o estudo do currículo para a criança pequena. Nesse "empréstimo", muitas vezes, também se observa um saber-fazer docente muito aderido a representações culturais historicamente cristalizadas sobre professor e escola (representações que influenciam práticas reprodutoras de um “currículo emprestado”). A CP1 explicita, sobretudo, esse movimento em relação ao trabalho com as crianças bem pequenas:

Não existe representação cultural de professor de bebês ainda. Porque mesmo os professores de bebês nunca foram crianças de creche. Ninguém brinca de ser professor de bebês. Por isso somos tão invisíveis. Porque não existe. Mesmo que você frequentasse creche de 30 anos atrás, não era com professor. É uma constituição identitária que está se fazendo. Então o que a professora pega enquanto representação cultural? $O$ papel de mãe e o papel de professor de EMEI/EMEF. Para tentar sacar qual é a dela. Não é? Até na apresentação da professora de CEI, quando ela faz uma reunião de pais, ela diz assim, "oh, eu sou professora, eu fiz faculdade, mas eu também sou mãe." Ela já está dizendo que papeis ela vai colocar em ação. Quando ela fala "professora" olha todo o conjunto de representações que ela tem. Quando ela fala "mãe", olha o conjunto... (CP1, entrevista).

O excerto mostra a influência dessas representações culturais para a construção do currículo em ação - sem representatividade, as professoras do Centro de Educação Infantil, por exemplo, exerceriam uma bricolagem entre os papeis de mãe e de professora para construírem seu papel. Nesse espaço, a coordenadora afirma a importância dos documentos centrais enquanto "eixos" para "aproximar a professora da possibilidade de construir outras representações culturais, de ancorar suas representações em referenciais mais reflexivos" (CP1, entrevista). 
As duas coordenadoras assumem as DCNEI (2009) como documento que deve nortear o trabalho com o currículo na escola. A CP1 afirma que com o trabalho de leitura desse documento, “eu trago para essa professora um ambiente promotor de reflexão sobre o próprio papel do professor" (CP1, entrevista). Ao fazer isso, CP1 está questionando representações mais tradicionais ou vinculadas ao trato assistencialista de outrora. Ainda sobre as Diretrizes, as coordenadoras afirmam que "a gente tem um documento muito progressista. Então, é verdade. Mudaram as marcações legais" (CP1, entrevista). No entanto,

A gente observa que existem muitos documentos, eu acho até que são documentos muito bons, progressistas, que dá para alicerçar o trabalho, mas o sentido que as professoras, a equipe gestora, dá para aquele documento, está muito longe (CP2, entrevista).

Através das falas destacadas, é possível compreender a distância entre o currículo prescrito (elaborado pelos formuladores de políticas públicas) e o currículo em ação (construído no cotidiano da escola). A fala das coordenadoras nos mostram um reconhecimento e a valorização de avanços nos discursos presentes nos textos curriculares da Educação Infantil, mas também o quanto ainda está "longe" a concretização dessas ideias "progressistas".

Essa constatação nos mostra que o exercício de construção curricular não funciona por meio de determinações legais. Mesmo sendo as DCNEI consideradas avançadas pelas profissionais da educação, ainda assim, para a constituição do currículo escolar em ação, na prática, um amplo exercício de mediações e reflexões coletivas deverá ser feito, a fim de (re)formular práticas pedagógicas em diálogo com os diferentes aspectos e princípios propostos no documento.

Nessa direção, as coordenadoras entrevistadas relatam desafios de trabalhar com as apropriações dos significados trazidos no texto nos momentos de formação. É importante aqui ressaltar que a ideia de apropriação, em uma perspectiva sócio-histórica, não significa simplesmente adequar a ação a alguma situação. Tal como Smolka (2000, p. 32) ressalta, tornar próprio não significa exatamente, e nem sempre coincide, com tornar adequado às expectativas sociais. Existem modos de tornar próprio, de tornar seu, que não são adequados ou pertinentes para o outro.

É essa complexidade que envolve os processos formativos da escola. Há expectativas do sistema, das gestoras, das professoras, da comunidade escolar em geral, bem como os significados que emergem nas interações com as próprias crianças, que ora convergem ora divergem, e há também os sujeitos em seus processos constantes de construção de significados em torno das práticas pedagógicas, no movimento instituído e instituinte da dialética histórica. 
Para as duas profissionais, a interpretação ativa, por parte da equipe pedagógica, dos conceitos que marcam a concepção de criança e as concepções de aprendizagem, devem nortear o trabalho formativo. Na prática, as coordenadoras organizam os momentos de formação planejando aproximações sucessivas da equipe de professoras e do contexto sócio histórico, que resulta nas atuais documentações curriculares - essa lógica de construção da concepção de criança também está presente em documentos curriculares como a DCNEI, o que sugere a influência do documento para a formação das coordenadoras.

As duas coordenadoras, ao discutirem o cenário de apropriação de documentos curriculares que consideram progressistas, se alongam em destaques para o momento de produção desses documentos, ou, nas falas da CP2, para o "pano de fundo" que caracteriza a produção desses textos. Para a CP2, “a leitura das Diretrizes é um texto difícil para as professoras” porque elas não possuem conhecimentos prévios sobre a sociologia da infância - ela cita que, sobretudo, as professoras mais antigas tiveram uma formação muito marcada por aspectos relacionados ao desenvolvimento das crianças, dentro de uma perspectiva de Psicologia, pautado por faixa etária (Rossetti-Ferreira e cols., 2009). Nesse cenário, faz menos sentido falar sobre "interação" e "experiência", termos chaves das DCNEI. Por isso, ela sente a necessidade de sempre resgatar o "pano de fundo" para situar as professoras sobre "o contexto, o lugar de onde estou falando sobre, por exemplo, a brincadeira" (CP2, entrevista).

As falas das entrevistadas a respeito das próprias interpretações sobre as DCNEI nos permitem afirmar que, constantemente, cotejaram concepções de criança, de professor e de Educação Infantil presentes em diferentes momentos da história da Educação Infantil, para compreenderem uma "marcação" que resulta em uma concepção de criança enquanto sujeito social. Da mesma maneira, as duas coordenadoras evidenciam a importância de encontrar estratégias que permitam às professoras refletirem sobre essas "marcações", mostrando que sem uma contextualização da construção dessa concepção de criança presente no texto curricular da Diretriz, por exemplo, não é possível ancorar práticas pedagógicas que validem o currículo proposto. As falas da CP2 acrescentam dados ao contexto apresentado pela CP1 - "Eu sei que sou a mediadora entre a documentação que está lá e aquilo que é o currículo, que acontece na escola [...] só os documentos não possibilitam essa mudança na prática". O que as coordenadoras nos mostram é que não basta apenas incorporar a leitura dos documentos na rotina das professoras ou mesmo reproduzir os termos ali contidos; é preciso uma observação crítica da prática. 
Se você perguntar para elas [as professoras], elas vão repetir, até em coro, "brincando a criança aprende; os materiais são muito importantes". Porque isso vem do texto oficial. Vem do RCNEI ${ }^{2}$. O documento central, ele comunica, mas ele não problematiza no nível da prática. Justamente por isso, é preciso dessa problematização daquilo que está no documento central. (CP1, entrevista)

Assim, ao criticar o modelo transmissivo de formação, indica também que é preciso complementar o documento pela problematização da prática. Esse é um papel que, como coordenadora, por meio de suas interpretações do documento, procura cumprir, propondo estratégias, principalmente via problematização do cotidiano da escola e observação crítica da prática: "E então eu vou observar a brincadeira, e questionar: como dois carrinhos sem roda e uma boneca amassada apoiam as construções das crianças?” (CP1, entrevista).

Também próxima da realidade que observa, ao se questionar sobre a lentidão das apropriações da documentação central pelos currículos das escolas na ação, a CP2 sugere que ainda é muito marcado o discurso das profissionais da Educação Infantil pelo Referencial Curricular Nacional para a Educação Infantil, ou seja, documento anterior, de 1996. Afirma também que a documentação curricular mais recente traz muitos princípios da "sociologia da infância, que foi chegar para a gente não faz tanto tempo assim" (CP2, entrevista).

A entrevistada cita que, naquele momento do Referencial, houve uma maior divulgação desses documentos, em um cenário onde as professoras de Educação Infantil estavam sedentas por uma valorização de seu espaço enquanto educadoras e por orientações curriculares que afirmassem a especificidade da Educação Infantil. Em comparação com o atual momento, a entrevistada avalia que, para ela, as discussões trazidas pelas Diretrizes fazem sentido, mas vê dificuldade em transformar essas discussões em prática pedagógica (e, sugerimos, em trabalho formativo). Sobre o RCNEI, Cerisara (2002) aponta como avanço o uso de termos presentes na atual discussão acadêmica sobre Educação Infantil (sobretudo no volume introdutório), demarcando um espaço de discussão já anunciado pelas publicações anteriores sobre criança enquanto sujeito social e o espaço da Educação Infantil, enquanto específico para atender o cuidado, a educação e a brincadeira. Entre os desafios, está a tradução desses princípios para a organização curricular, expressa principalmente nos volumes 2 e 3 - onde o texto sugere a organização do currículo por eixos de trabalho e, assim, mostra-se muito mais próximo da organização do Ensino Fundamental do que da própria Educação Infantil. Questões relativas ao objetivo que o documento se propõe atingir - "contribuir para a formação de crianças felizes e

${ }^{2}$ Referencial Curricular Nacional para a Educação Infantil, publicado em 1998. 
saudáveis" (BRASIL, 1998, p. 23) - também mostram que, naquele momento, ainda havia resquícios da tradição de uma educação compensatória nos discursos sobre Educação Infantil, o que é superado no documento das DCNEI.

Ao conceituar a criança não apenas como sujeito social e cultural, mas como sujeito produtor de cultura e nela inserido (BRASIL, 2009, p. 8), o texto das DCNEI impacta o trabalho com o currículo: entender que a criança está inserida na cultura, além de ser também ela produtora de cultura, implica descentralizar o adulto enquanto "transmissor" de uma cultura pronta para um ser "em desenvolvimento" - no errôneo sentido de um ser incompleto, que está se preparando para ser completo.

Em suas falas, as Coordenadoras afirmam que as marcações legais não traduzem a realidade do currículo em ação, confirmando nossa compreensão de que as escolas possuem uma "autonomia relativa de ação", ao mesmo passo em que são influenciadas por representações culturais mais fortes do que as próprias mudanças legais. Podemos apontar, a partir das construções aqui colocadas, que, para o trabalho formativo em torno dos documentos curriculares, no sentido de apoiarem o planejamento e a condução das práticas pedagógicas, são necessárias mudanças também no âmbito da formação dos coordenadores, corroborando as reflexões de Placco, Souza e Almeida (2012) de que as demandas de trabalho têm demandado, muitas vezes, além das possibilidades reais de ação desses profissionais.

A CP1 indica que os desafios em torno da formação do coordenador pedagógico permanecem: a entrevistada chama atenção para a formação continuada dos CPS, que se dá de maneira transmissiva, sem as devidas problematizações encontradas no cotidiano. Além disso, a entrevistada coloca que os coordenadores "não viveram na sua própria história, a questão de uma criança ser [considerada] sujeito [produtor de cultura], nem a questão da experiência enquanto promotora de desenvolvimento!" (CP1, entrevista), portanto, precisam de referências que os apoiem a enxergar uma prática pedagógica que traga esses princípios como norteadores do planejamento das professoras.

Ao falarem sobre as marcações destes documentos, usam expressões sempre muito próximas - nas duas falas aparecem termos como "escuta da infância, experiência, campos de experiência, linguagens da infância e aprendizagem ativa" para elucidarem as marcações teóricas dos documentos legais. Para a CP2, esses termos são resultado da psicologia sociocultural e da área de conhecimento da sociologia da infância que, em sua leitura, é uma forte influência para as Diretrizes Curriculares Nacionais para a Educação Infantil. Aqui, destacamos: a construção é histórica e inter-relaciona conquistas também de outras áreas específicas, como a história, 
antropologia e a neurociência, que, em seus campos próprios de estudo, passam a fortalecer o olhar sobre a criança enquanto sujeito social e os desdobramentos dessa concepção para seu desenvolvimento.

As falas das coordenadoras mostram a dinamicidade do movimento teórico elucidado, em uma apropriação interpretativa dos documentos curriculares na construção do cotidiano da Educação Infantil. E, para além disto: não só situam os documentos em um contexto maior de produção, como valorizam interpretá-lo em relação às articulações possíveis com o currículo das escolas.

Durante as entrevistas, as coordenadoras fazem menções a práticas das próprias unidades escolares, descrevendo o percurso formativo que hoje está traçado nesse processo de discussão de um currículo. Fortalecer o horário coletivo de trabalho, a observação do cotidiano da escola, a modificação/organização de espaços e materiais e as devolutivas sobre as propostas realizadas pelas professoras são algumas das estratégias formativas planejadas pelas coordenadoras entrevistadas.

Em relação ao horário coletivo de trabalho, os objetivos declarados se aproximam quando as entrevistadas afirmam esse espaço enquanto responsável por triangular o Projeto Político Pedagógico da unidade aos documentos oficiais e às discussões sobre as práticas da escola - "o documento precisa suscitar questões sobre a prática - e a prática precisa encontrar no documento razões para se sustentar" (CP1, entrevista) - no entanto, as coordenadoras imprimem marcas pessoais em relação a sua condução.

No caso do CEI, a coordenadora apresentou a discussão sobre as DCNEI centrando-se em definir o que é experiência para, a partir do conceito, organizar um currículo que valorize as experiências das crianças. A coordenadora afirma que discutir a experiência dentro do currículo não é uma questão de "técnica, de prescrição", mas sim, de compreender o conceito e de observar o cotidiano problematizando-o de maneira coletiva. Nesse processo de estudo da prática, as discussões centraram-se na reorganização do planejamento, pensando em problematizar modelos de planejamento por horário e atividade e que buscam observar e desafiar as crianças em suas pesquisas. A CP1 acredita que "enquanto as professoras não significarem o que é experiência e porque discutimos experiência ao falar de desenvolvimento humano", existirá fragilidade na construção de um currículo que valorize essa experiência - nesse caso, é ainda mais complexa a atuação do coordenador, pois atua com uma documentação progressista em relação ao espaço da experiência, mas com vivências ancoradas em representações muito tradicionais.

No caso da EMEI, a Coordenadora sinaliza que procura avançar em relação à necessidade de escutar a criança e planejar devolutivas que valorizem a escuta e os saberes que as crianças são 
capazes de construir - para ela, "não adianta só o professor ter o conteúdo das teorias; ele precisa cruzar... E na hora que o professor não sabe alimentar, não tem como cruzar, ele dá a resposta...”. Transpondo essa problemática para a prática, a CP2 exemplifica:

Por exemplo, uma professora aqui está fazendo um trabalho bem legal nessa
perspectiva de experiência com as crianças... Sobre a água... Então tiveram
pontos interessantes... Aproximações, problematização, discussão,... Mas daí,
quando chegou um certo ponto, ela não se aguentou. Ela precisava ir para a lousa.
Ela desenhou todo o ciclo da água para as crianças de quatro anos. Eu olhei
aquilo e pensei: 'nossa, o que será que essa criança compreendeu desse desenho?
Desse gráfico que não foi produzido por ela?' Uma coisa é a criança produzir e
ela me dizer qual é a lógica de pensamento dela, quais são suas hipóteses sobre
determinados eventos (que era o que ela estava fazendo!!!) Outra coisa é a
professora fazer, cheia de setinhas, ali,.. Então, isso me mostra muitas coisas. Se
vê que ela está construindo ali, na sala de aula, as próprias hipóteses sobre o
desenvolvimento infantil. Por algum motivo, ela mesma não se contentou com
as respostas que as crianças tinham construído até ali e quis fundamentar de outro
jeito, sistematizar, sob o viés do olhar/da produção do adulto (CP2, entrevista).

As falas traduzem questões inerentes ao trabalho do coordenador em torno das articulações necessárias para a construção de um currículo para a Educação Infantil, que efetivamente incorpore as conquistas dos textos oficiais: reflexões em torno do papel do professor/da escola enquanto propositor e organizador de experiências e o planejamento do professor, de maneira que assegure a autoria da criança. Ao mesmo tempo, valorizam a experiência das professoras e a responsabilidade de "alimentar as reflexões e não de dar resposta" (CP2, entrevista).

A formação proposta nos dois espaços parece-nos ter a vantagem de, a partir da problematização crítica das práticas locais, cotejar tanto aspectos referentes ao desenvolvimento da área da Educação Infantil, quanto o da interpretação dos conceitos trazidos nas documentações centrais, o que é válido se pensarmos que o Coordenador ocupa lugar privilegiado enquanto articulador entre os programas oficiais e a prática cotidiana das escolas.

\section{Considerações finais}

Esse texto busca contribuir com o atual momento de homologação de uma proposta renovada de educação infantil, formalizada no documento curricular, a Base Nacional Comum Curricular (Brasil, 2017) - documento este que, por sua vez, traz decorrências das Diretrizes Curriculares Nacionais para a Educação Infantil (Brasil, 2009) -, destacando elementos no cenário de articulação entre currículo prescrito e currículo em ação.

Privilegiamos um olhar para as escolas para compreender como a interpretação de duas 
coordenadoras sobre os documentos oficiais marca a reflexão sobre a organização das práticas cotidianas, junto à equipe. O coordenador tem papel importante nesse aspecto, pois, como previsto tanto pela documentação municipal quanto pelas próprias entrevistadas, atua em lugar privilegiado, desenvolvendo ações que aproximem o currículo prescrito do currículo em ação.

Tivemos contato com realidades onde existe uma possível concentração do trabalho do coordenador no exercício da formação continuada centrada na escola. Isso não necessariamente acontece em outras unidades ou redes de Educação Infantil, o que indica contextos distintos para outros estudos.

A análise das falas aponta para a construção de conceitos no campo teórico da Educação Infantil marcados, principalmente, pela afirmação do papel do professor (especialização da docência), do currículo (proximidade com o cotidiano escolar) e da criança (sujeito da Educação Infantil). Essas afirmações traduzem historicamente a demarcação do espaço do conhecimento teórico específico da Educação Infantil, que até então tivera por tanto tempo conhecimentos 'emprestados' da filosofia e da psicologia. Contribuições relevantes, mas que não substituem as construções da Pedagogia.

Observamos atuações profissionais críticas em relação aos seus percursos formativos, propositoras de reflexões em torno das transformações do conceito de criança e atentas à necessidade de intervenções na escola no sentido de problematizar tempos, espaços e materiais de maneira coletiva, optando por estratégias de formação que efetivamente possibilitem práticas docentes respeitosas, no que trazem de mais específico: o trato pedagógico com a infância.

Em suas singularidades, concluímos que os espaços formativos se fortaleceram a partir de decisões das coordenadoras que possibilitaram:

- a reflexão sobre a própria prática enquanto formadoras de professoras,

- a busca por inovação/reinvenção dos tempos, espaços e materiais na Educação Infantil, enquanto propositoras de reflexões sobre cotidiano e

- o fortalecimento do trabalho com as questões que mobilizam os professores em direção a (re)significação de duas formas de pensar, sentir e agir na Educação Infantil (o que exige competência, observação crítica e delicadeza no sentido de identificar e atuar nas necessidades formativas da equipe).

Nos dois contextos de Educação infantil, considerar os aspectos apontados acima significa organizar um trabalho a partir das necessidades da realidade escolar, valorizando as reflexões desenvolvidas ou a serem desenvolvidas pela equipe com o apoio, entre outros, do estudo das 
documentações curriculares centrais.

O cenário nos convida a investigações que ressaltem a questão do investimento das políticas públicas e também das instituições de ensino superior na formação inicial e continuada do coordenador pedagógico. As coordenadoras entrevistadas se reconhecem enquanto formadoras e afirmam o espaço dos documentos curriculares nessas formações, mas as entrevistas nos mostram que as iniciativas são mais resultado de buscas particulares, do que integradas a iniciativas dos órgãos centrais. Acrescidos a esse cenário, a própria figura do coordenador dentro das escolas, cuja atuação é marcada pela "conquista de um território próprio" (MATE, 2005), pois, como foi reforçado pelas coordenadoras, trata-se de uma função ainda muito solitária.

Sem uma formação que promova o desenvolvimento profissional do coordenador no lugar de formador da equipe, a construção de um currículo para a infância tende a se fragilizar nas expectativas de construção de uma prática que articule efetivamente os saberes e experiências das crianças e os conhecimentos que fazem parte do patrimônio cultural.

\section{Referências}

BARBOSA, Ma. Carmen Silveira. Os resultados da avaliação de propostas curriculares para a educação infantil dos municípios brasileiros. Anais do I Seminário Nacional: Currículo em movimento. Perspectivas Atuais: Belo Horizonte, 2010. Disponível em:

http://portal.mec.gov.br/docman/dezembro-2010-pdf/7150-1-1-artigo-mec-propostacurricular-maria-carmem-seb/file, acesso em 23 de julho de 2020.

BRASIL. Ministério da Educação e do Desporto. Secretaria de Educação Fundamental. Referencial Curricular Nacional para a Educação Infantil. Brasília: SEF, v. 1, 2 e 3, 1998.

BRASIL. Ministério da Educação. Conselho Nacional da Educação. Diretrizes curriculares nacionais para a Educação Infantil. Brasília, DF, 2009.

BRASIL. Parecer no 15 de 21 de dezembro de 2017. Base Nacional Comum Curricular: BNCC. Conselho Nacional de Educação /Conselho Pleno. Brasília, DF, 2017.

CAMPOS, Maria Malta. Educação Infantil: o debate e a pesquisa. Cadernos de Pesquisa, São Paulo, n. 101, p. 113-127, jul. 1997. Disponível em:

http://publicacoes.fcc.org.br/ojs/index.php/cp/article/view/754, acesso em 23 de julho de 2020.

CAMPOS, Maria Malta; FULLGRAF, Jodete; WIGGERS, Verena. A qualidade da Educação Infantil brasileira: alguns resultados de pesquisa. Cadernos de Pesquisa, v. 36, n. 127, p. 87-128, jan./abr. 2006. Disponível em: https://www.scielo.br/pdf/es/v23n80/12935.pdf, acesso em 23 de julho de 2020. 
CIARDELLA, Thais Monteiro. A experiência do coordenador pedagógico em duas escolas municipais: desafios em tempos de definição do currículo para a Educação Infantil. São Paulo, 2016. 67 f. Trabalho de Conclusão de Curso de Pós-graduação (Especialização) em Gestão Pedagógica e Formação em Educação Infantil - Instituto Superior de Educação Vera Cruz, 2016.

CERISARA, Ana Beatriz. O Referencial Curricular Nacional para a Educação Infantil no contexto das reformas. Educação e Sociedade, Campinas, vol. 23, n. 80, setembro/2002, p. 326-345.

DAVIS, Claudia L. F.; Nunes, Marina M. R.; ALMEIDA, Patrícia C. A. de; SILVA, Ana Paula F. da e SOUZA, Juliana C. de. Formação continuada de professores: uma análise das modalidades e das práticas em estados e municípios brasileiros. São Paulo: FCC/DPE, 2012. Disponível em: http://publicacoes.fcc.org.br/ojs/index.php/textosfcc/article/view/2452/2407, acesso em 23 de julho de 2020.

LIMA, Licínio Carlos. A escola como organização educativa: uma abordagem sociológica. $3^{a}$ ed. São Paulo: Cortez, 1998.

LUDKE, Menga; ANDRÉ, Marli. Pesquisa em educação: abordagens qualitativas. São Paulo: EPU, 1986.

MATE, Cecília Hanna. Qual a identidade do coordenador pedagógico? In: GUIMARÃES, Ana Arqueangelo. et al. O coordenador pedagógico e a educação continuada. São Paulo, Loyola, 2005. P. $17-20$.

ROSSETTI FERREIRA, Maria Clotilde; AMORIM, Katia de Souza; OLIVEIRA, Zilma Moraes Ramos de. Olhando a criança e seus outros: uma trajetória de pesquisa em educação infantil. Psicologia USP, São Paulo, vol. 3, n. 20, julho/setembro, 2009, 437-464. Disponível em: http://pepsic.bvsalud.org/scielo.php?script=sci arttext\&pid=S1678-51772009000300008, acesso em 23 de julho de 2020.

GIMENO SACRISTÁN, José. El curriculum: uma reflexión sobre la practica. Madri: Morata, 1998.

SÃO PAULO. Secretaria Municipal de Educação. Currículo Integrador da Infância Paulistana. São Paulo/DOT, 2015.

OLIVEIRA, Zilma de Moraes Ramos de; FERREIRA, Marisa Vasconcelos e BARROS, Joseane Ap. Bomfim de. Formação Continuada em Educação Infantil: a construção de uma agenda de possibilidades. In Guimarães, Célia Ma.; Reis, Pedro Guilherme Rocha dos. Professores e infâncias: estudos e experiências. Araraquara-SP: Junqueira e Marin, 2011.

PLACCO, Vera Maria Nigro De Souza; SOUZA, Vera Lucia Trevisan De; ALMEIDA, Laurinda Ramalho De. O coordenador pedagógico: aportes à proposição de políticas públicas. Cad. Pesquisa, São Paulo, v. 42, n. 147, p. 754-771, dez. 2012. Disponível em http://www.scielo.br/scielo.php?script=sci arttext\&pid=S0100$15742012000300006 \& \operatorname{lng}=$ en\&nrm=iso, acesso em 23 de julho de 2020. 
SMOLKA, Ana Luiza Bustamante. O (im)próprio e o (im)pertinente na apropriação das práticas sociais. Cadernos Cedes, ano XX, no 50, abril/00. Disponível em:

http://www.scielo.br/pdf/ccedes/v20n50/a03v2050.pdf , acesso em 07/11/2019.

VERA, Rebeca Franciele; FERNANDES, Ma. José da Silva. Como se formam os professores coordenadores na rede estadual de ensino de São Paulo. Dialogia. São Paulo, n 33, p. 5-18, set./dez. 2019. Disponível em: https://doi.org/10.5585/dialogia.N33.13612, acesso em 23 de julho de 2020.

Recebido em: 11 nov. 2019/ Aprovado em: 25 jun. 2020

\section{$\underline{\text { Cite como }}$}

\section{(ABNT NBR 6023:2018)}

CIARDELLA, Thais Monteiro; FERREIRA, Marisa Vasconcelos. O currículo prescrito no cotidiano escolar: interpretações de Coordenadoras Pedagógicas da Educação Infantil. Dialogia, São Paulo, n. 35, p. 228-244, maio/ago. 2020. Disponível em:

https://doi.org/10.5585/dialogia.n35.16009.

\section{American Psychological Association (APA)}

Ciardella, T. M., \& Ferreira, M. V. (2020, maio/ago.). O currículo prescrito no cotidiano escolar: interpretações de Coordenadoras Pedagógicas da Educação Infantil. Dialogia, São Paulo, 35, p. 228-244. https://doi.org/10.5585/dialogia.n35.16009. 